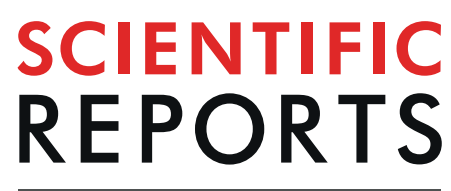

natureresearch

\title{
Relationship between Sleep Duration, Sun Exposure, and Serum 25-Hydroxyvitamin D Status: A Cross-sectional Study
}

\author{
Ji Ho Choi ${ }^{1}$, Bora Lee ${ }^{2}{ }^{2}$, Jae Yong Lee ${ }^{1}$, Chang-Hoon Kim ${ }^{3}$, Bumhee Park ${ }^{4,5}$, \\ Dong Young $\mathrm{Kim}^{6}$, Hyun Jun Kim ${ }^{6}$ \& Do-Yang Park $\mathbb{B}^{6,7^{*}}$
}

Normal-range sleep duration is an important factor for general health and metabolism, and insufficient or excessive sleep is associated with chronic metabolic disease. Among the many factors that affect sleep duration, sun exposure plays an important role in maintaining regular circadian rhythm and is also involved in the production and activation of 25 -hydroxyvitamin $\mathrm{D}[25(\mathrm{OH}) \mathrm{D}]$, which regulates various functions in the body. However, $25(\mathrm{OH}) \mathrm{D}$ is available through food and various nutritional supplements without sun exposure, so it is important to find out the complex relationship among sun exposure, vitamin $D$ status, and sleep duration. The relationship between sun exposure, vitamin $D$ status, and sleep duration was analyzed in the nationwide survey and examination of 25,534 study populations, after adjusting for demographic characteristics, physical characteristics, lifestyle status, and socio-demographic variables. Vitamin $D$ status alone did not show the relationship with sleep duration, although there were statistical relationships in the various factors including sun exposure with sleep duration. There was a statistical difference in $25(\mathrm{OH}) \mathrm{D}$ according to sleep duration, only in low sun exposure group. Subjects with low sun exposure and excessive sleep duration comparatively lower 25(OH)D than those with normal-range sleep, even after adjustment for potentially confounding factors. Individuals with limited exposure to sunlight should maintain adequate vitamin $D$ status to have an appropriate sleep duration for health.

Normal-range sleep duration is an important factor for general health and metabolism ${ }^{1}$. Insufficient or excessive sleep duration is associated with various chronic physical or mental illness, such as obesity, hypertension, diabetes, metabolic syndrome, depression, and other psychiatric disease ${ }^{2-4}$. Sleep insufficiency has been also associated with low thyroid hormone levels in rats and with high noradrenaline and cortisol levels in humans ${ }^{5}$. Sleep duration is mainly affected by circadian rhythm, and circadian rhythm is affected by the melatonin level controlled by the light exposure ${ }^{6-8}$. Therefore, sun exposure has an important role for determining sleep time ${ }^{9-11}$.

25 -hydroxyvitamin $\mathrm{D}[25(\mathrm{OH}) \mathrm{D}]$, which is also greatly affected by sunlight exposure, regulates the metabolism of calcium and phosphorus, which contribute to the maintenance of a healthy musculoskeletal system. Recent studies have suggested that vitamin D status are associated with impaired glucose metabolism, cardiovascular disease, infectious/inflammatory disease, psychiatric disease, and cancer ${ }^{12-16} .25(\mathrm{OH}) \mathrm{D}$ is produced either through an endogenous pathway using UV light from sun exposure or an exogenous pathway through food intake. Vitamin D status are mainly regulated through serum phosphorus and parathyroid hormone, but are also affected by temperature, skin color, sunscreen use, clothing, obesity, and hepatic or renal function ${ }^{17}$. Serum vitamin D status, measured as $25(\mathrm{OH}) \mathrm{D}$, are also implicated in an increasing number of physiological mechanisms,

${ }^{1}$ Department of Otorhinolaryngology-Head and Neck Surgery, Soonchunhyang University College of Medicine, Bucheon Hospital, Bucheon, Republic of Korea. ${ }^{2}$ Department of Statistics, Graduate School of Chung-Ang University, Seoul, Republic of Korea. ${ }^{3}$ Department of Otorhinolaryngology, Yonsei University College of Medicine, Seoul, Republic of Korea. ${ }^{4}$ Department of Biomedical Informatics, Ajou University School of Medicine, Suwon, Republic of Korea. ${ }^{5}$ Office of Biostatistics, Ajou Research Institute for Innovative Medicine, Ajou University Medical Center, Suwon, Republic of Korea. ${ }^{6}$ Department of Otolaryngology, Ajou University School of Medicine, Suwon, Republic of Korea. ${ }^{7}$ Department of Medicine, Yonsei University Graduate School, Seoul, Republic of Korea. *email: entdyp@ ajou.ac.kr 
including sleep ${ }^{18}$. The $25(\mathrm{OH}) \mathrm{D}$ receptor is widely distributed among tissues, including the regions of the brain involved in sleep regulation and central nervous system inflammatory signaling ${ }^{19-21}$. The circadian phase of sleep can be delayed by vitamin $\mathrm{D}$ supplementation and by sun exposure ${ }^{22,23}$. Finally, serum vitamin $\mathrm{D}$ status have been related to daytime sleepiness ${ }^{24}$, and epidemiologic studies have indicated that vitamin D status are associated with the mid-point of sleep, sustained sleep, and sleep duration in the elderly ${ }^{25-27}$.

Modern human life often results in insufficient sun exposure, so it is important that $25(\mathrm{OH}) \mathrm{D}$ studies consider this factor. The complex metabolic process of production and activation of $25(\mathrm{OH}) \mathrm{D}$ by sun exposure, and the fact that $25(\mathrm{OH}) \mathrm{D}$ can be supplemented by exogenous methods, such as food or nutritional supplementation, without endogenous process of sun exposure implies that various related factors, including sun exposure, must be considered in analyzing the relationships between sleep duration and 25(OH)D. Therefore, we designed our study to analyze the relationship between vitamin D status, sleep duration, and sun exposure after controlling for a number of potentially confounding variables.

\section{Methods}

Study population. The Korean National Health and Nutrition Examination Survey (KNHANES) is a nationwide survey conducted by the Korea Centers for Disease Control and Prevention, in conjunction with the Korean Society of Otorhinolaryngology-Head and Neck Surgery (KORL-HNS) and other societies. KNHANES was initiated in 1998 to record the health and nutritional status of the Korean population and was designed as a multistage, cross-sectional, stratified sampling study without overlapping subjects. Teams of four medical experts, including an otolaryngologist, conducted the clinical examinations nationwide, using a specially equipped mobile examination vehicle. All questionnaires were completed, samples taken, and examinations performed for each subject in a single visit. KORL-HNS trained the survey teams to standardize the examinations. Our study was conducted on KNHANES data obtained between 2010 and $2012(\mathrm{n}=25534)$. A total of 14490 participants were included in the final study population after the exclusion of participants aged less than 19 years $(n=5,935)$ and those with missing relevant data $(n=5,109)$. The mean age of study participants was $50.84 \pm 16.26$ years (range, 19-97 years) and the male to female ratio was 1:1.47. The survey protocol was approved by the institutional review board of the Korea Centers for Disease Control and Prevention (IRB Nos. 2010-02CON-21-C, 2011-02CON06-C, and 201201EXP-01-2C). All study participants provided written informed consent as part of KNHANES.

Assessment of sleep duration and sun exposure. Self-reported sleep duration was assessed through a questionnaire. A KNHANES nurse asked survey participants "How many hours a day do you usually sleep?" and recorded their response ${ }^{28}$. From this response, sleep duration was divided into three groups: less than 6 hours, 6 to 9 hours, and more than 10 hours. To assess daily sun exposure, the participants were asked, "What is the average duration of your direct exposure to sun during the day?" for which participants were given the options: less than 2 hours, 2 to 5 hours, and 5 hours or more.

Measurement of serum 25-hydroxy vitamin D status. Blood samples were collected via the antecubital vein the morning after a minimum fast of 8 hours and refrigerated immediately. Samples were transported to the central testing facility in cold storage and analyzed within $24 \mathrm{~h}$. Serum levels of $25(\mathrm{OH}) \mathrm{D}$ were measured by radioimmunoassay $\left(25(\mathrm{OH}) \mathrm{D}^{125} \mathrm{I}\right.$ RIA Kit; DiaSorin, Still Water, MN) using a gamma-counter (1470 Wizard; PerkinElmer, Turku, Finland). The inter assay coefficients of variation were $11.7 \%, 10.5 \%$, and $8.6 \%$ at 21.47 , 56.66 , and $82.37 \mathrm{nmol} / \mathrm{L}$, respectively. KNHANES participates in the Vitamin D Standardization Program, so the measurement of $25(\mathrm{OH}) \mathrm{D}$ was standardized with the Belgian National Institute of Standards and Technology reference procedure recently developed by Ghent University ${ }^{29}$. Although there has been much debate over the definition of vitamin D deficiency, it is generally accepted that a $25(\mathrm{OH}) \mathrm{D}$ concentration of $20 \mathrm{ng} / \mathrm{mL}$ is an indication of deficiency ${ }^{30-32}$.

Statistical analysis. Statistical analyses were performed using the SAS survey procedure (ver. 9.4; SAS Institute, Cary, NC, USA) because of the complex sampling design and sampling weights from KNHANES. The procedure accommodated unequal probabilities of selection, oversampling, and non-response. Participants' characteristics were analyzed using mean and standard error for continuous variables and value and percentage for categorical variables. To analyze differences in serum vitamin D status between sleep duration groups, the Rao-Scott chi-square test (using PROC SURVEYFREQ in SAS) was used. The exponentiated beta coefficients and 95\% confidence intervals (CIs) for log-transformed vitamin D status were calculated.

Multiple logistic regression analysis (using PROC SURVEYLOGISTIC in SAS) was used to determine the association between $25(\mathrm{OH}) \mathrm{D}$, sun exposure, and sleep duration. The crude dataset (model 1) was adjusted for age and sex (model 2). Model 2 was then adjusted for physical status (obesity, prevalent hypertension [HTN], prevalent diabetes [DM], and prevalent dyslipidemia) to generate model 3. Finally, model 3 was adjusted for lifestyle status (smoking status, drinking status, and regular exercise) and socio-demographic factors (family income, educational level, occupation, and region of residence), generating model 4 . Two-tailed $\mathrm{p}$ values were generated, and a $\mathrm{p}<0.05$ was considered significant.

Ethical approval. All procedures performed in the studies involving human participants were in accordance with the ethical standards of the institutional and/or national research committee and with the 1964 Helsinki declaration and its later amendments or comparable ethical standards.

Informed consent. Informed consent was obtained from all individual participants included in the study. 


\begin{tabular}{|c|c|c|c|c|c|c|}
\hline \multirow{2}{*}{\multicolumn{2}{|c|}{ Variable }} & \multirow{3}{*}{$\mathbf{N}$} & \multicolumn{4}{|c|}{ Sleep duration (hours/day) } \\
\hline & & & \multirow{2}{*}{$\begin{array}{l}<6 \\
2226(13 \%)\end{array}$} & \multirow{2}{*}{\begin{tabular}{|l|}
6 to 9 \\
$11798(84 \%)$ \\
\end{tabular}} & \multirow{2}{*}{$\begin{array}{l}\geq 10 \\
466(3 \%)\end{array}$} & \multirow[t]{2}{*}{ p-value } \\
\hline $\mathrm{N}$ & & & & & & \\
\hline \multirow{6}{*}{ Age (years) } & $19-29$ & 1586 & $10.6(1)$ & $20(0.7)$ & $39.5(1)$ & $<0.01$ \\
\hline & $30-39$ & 2612 & $11.2(1)$ & $22.6(0.7)$ & $10.4(2)$ & \\
\hline & $40-49$ & 2556 & $19.3(1)$ & $22.9(0.6)$ & $13.7(2)$ & \\
\hline & $50-59$ & 2867 & $20.3(1)$ & $18.5(0.5)$ & $15.4(2)$ & \\
\hline & $60-69$ & 2609 & $18(1)$ & $9.5(0.3)$ & $10.7(1)$ & \\
\hline & $\geq 70$ & 2260 & $20.5(1)$ & $6.4(0.3)$ & $10.3(1)$ & \\
\hline \multirow{3}{*}{ Sex } & Male & 5869 & $40.9(1)$ & $51.6(0.5)$ & $50.4(3)$ & $<0.01$ \\
\hline & Menstruating women & 4271 & $21.1(1)$ & $31.6(0.5)$ & $34.9(3)$ & \\
\hline & Menopausal women & 4350 & $38(1)$ & $16.8(0.4)$ & $14.8(2)$ & \\
\hline \multirow{3}{*}{ Obesity } & Underweight & 634 & $2.9(0.4)$ & $4.8(0.3)$ & $6.9(2)$ & $<0.01$ \\
\hline & Normal & 9234 & $62.3(1)$ & $63.4(0.6)$ & $62.6(3)$ & \\
\hline & \begin{tabular}{|l|} 
Overweight \\
\end{tabular} & 4585 & $34.8(1)$ & $31.8(0.6)$ & $30.5(3)$ & \\
\hline \multirow{2}{*}{ Hypertension } & No & 11043 & $72.3(1)$ & $84.4(0.5)$ & $85.1(2)$ & $<0.01$ \\
\hline & Yes & 3447 & $27.7(1)$ & $15.6(0.5)$ & $14.9(2)$ & \\
\hline \multirow{2}{*}{ Diabetes } & No & 13241 & $90.2(0.7)$ & $94.2(0.3)$ & $93.8(1)$ & $<0.01$ \\
\hline & Yes & 1249 & $9.8(0.7)$ & $5.8(0.3)$ & $6.2(1)$ & \\
\hline \multirow{2}{*}{ Dyslipidemia } & No & 12798 & $87(1)$ & $92.1(0.3)$ & $93.2(1)$ & $<0.01$ \\
\hline & Yes & 1692 & $13(1)$ & $7.9(0.3)$ & $6.8(1)$ & \\
\hline \multirow{3}{*}{ Smoking status } & Non-smoker & 8829 & $60.2(1)$ & $53(0.5)$ & $48.2(3)$ & $<0.01$ \\
\hline & Ex-smoker & 2967 & $18.7(1)$ & $20.9(0.5)$ & $20.5(2)$ & \\
\hline & Smoker & 2694 & $21.1(1)$ & $26.1(0.6)$ & $31.3(3)$ & \\
\hline \multirow{3}{*}{ Alcohol consumption } & None & 4186 & $32.4(1)$ & $20.8(0.5)$ & $25.2(3)$ & $<0.01$ \\
\hline & Occasional ( $<2 /$ week $)$ & 7416 & $45.7(1)$ & $56.0(0.6)$ & $50.3(3)$ & \\
\hline & Frequent ( $\geq 2 /$ week) & 2888 & $21.9(1)$ & $23.2(0.5)$ & $24.5(3)$ & \\
\hline \multirow{2}{*}{ Regular exercise } & No & 7694 & $51.1(2)$ & $51.4(0.7)$ & $55.3(3)$ & 0.35 \\
\hline & Yes & 6796 & $48.9(2)$ & $48.6(0.7)$ & $44.7(3)$ & \\
\hline \multirow{2}{*}{ Region of residence } & Rural & 4844 & $30.4(2)$ & $29.1(1)$ & $36.9(3)$ & 0.01 \\
\hline & Urban & 9646 & $69.6(2)$ & $70.9(1)$ & $63.1(3)$ & \\
\hline \multirow{2}{*}{ Family income } & $<50^{\text {th }}$ percentile & 6573 & $52.9(2)$ & $40.5(1)$ & $52.7(3)$ & $<0.01$ \\
\hline & $\geq 50^{\text {th }}$ percentile & 7917 & $47.1(2)$ & $59.5(1)$ & $47.3(3)$ & \\
\hline \multirow{2}{*}{ Educational level } & $\begin{array}{l}\text { Middle school } \\
\text { or lower }\end{array}$ & 5397 & $48.3(1)$ & $24.4(0.7)$ & $33.8(3)$ & $<0.01$ \\
\hline & High school or higher & 9093 & $51.7(1)$ & $75.6(0.7)$ & $66.2(3)$ & \\
\hline \multirow{3}{*}{ Occupation } & White collar & 4604 & $27.1(1)$ & $39.7(0.7)$ & $24.7(3)$ & $<0.01$ \\
\hline & Blue collar & 3887 & $29.7(1)$ & $27.4(1)$ & $23.7(3)$ & \\
\hline & Unemployed & 5999 & $43.1(1)$ & $32.9(0.6)$ & $51.6(3)$ & \\
\hline \multirow{2}{*}{$\begin{array}{l}\text { Exposure to sunlight } \\
\text { (hours/day) }\end{array}$} & $<2$ & 9173 & $59.2(2)$ & $63.5(1)$ & $58.1(3)$ & $<0.01$ \\
\hline & $\geq 2$ & 5317 & $40.8(2)$ & $36.5(1)$ & $41.9(3)$ & \\
\hline \multirow{2}{*}{$25(\mathrm{OH}) \mathrm{D}(\mathrm{ng} / \mathrm{mL})$} & $<20$ & 10217 & $71.1(2)$ & $71.7(1)$ & $74.4(3)$ & 0.48 \\
\hline & $\geq 20$ & 4273 & $28.9(2)$ & $28.3(1)$ & $25.6(3)$ & \\
\hline
\end{tabular}

Table 1. Baseline characteristics by sleep duration. Data were reported as weighted percentage (SE). p-Values were calculated by Rao-Scott chi-square test.

\section{Results}

Baseline characteristics and associations with sleep duration. A total of 14490 enrolled participants were divided into three groups according to sleep duration: normal-range sleep group (' 6 to 9 hours', 83.6\%), sleep insufficient group ('less than 6 hours', $13 \%$ ), and excessive sleep group ('more than 10 hours', 3.4\%). Data were analyzed to identify statistical differences between groups in terms of age, sex, obesity, HTN, DM, dyslipidemia, smoking status, alcohol consumption, regular exercise, region of residence, family income, education level, occupation, exposure to sunlight, and vitamin D status (Table 1). All factors differed between groups apart from regular exercise and vitamin D status. In the excessive sleep group, participants were more likely to be younger, non-hypertensive, non-dyslipidemic, and menstruating women. In the sleep insufficient group, participants tended to be older, overweight, relatively hypotensive, DM, dyslipidemic, non-smokers, non-alcohol drinkers, and menopausal women. The percentage of residents living in urban areas was higher in the sleep insufficient group than in the excessive sleep group. Participants with low sun exposure were most likely to be in the normal-range sleep group than in the sleep insufficient or excessive sleep group. Vitamin D status were not significantly different between sleep duration groups prior to adjustment for potentially confounding factors. 


\begin{tabular}{|c|c|c|c|c|c|c|}
\hline \multirow{2}{*}{\multicolumn{2}{|c|}{ Variable }} & \multirow[b]{2}{*}{$\mathbf{N}$} & \multirow{2}{*}{\begin{tabular}{|l}
$25(\mathrm{OH}) \mathrm{D}(\mathrm{ng} / \mathrm{mL})$ \\
Geometric mean $(\mathrm{SE})$
\end{tabular}} & \multirow{2}{*}{\begin{tabular}{|l|}
$25(\mathrm{OH})$ \\
$\mathrm{D}<20 \mathrm{ng} / \mathrm{mL}$ \\
$\%(\mathrm{SE})$ \\
\end{tabular}} & \multirow{2}{*}{$\begin{array}{l}25(\mathrm{OH}) \\
D \geq 20 \mathrm{ng} / \mathrm{mL} \\
\% \text { (SE) }\end{array}$} & \multirow[b]{2}{*}{ p-value } \\
\hline & & & & & & \\
\hline Total & & & $16.3(1)$ & $71.7(1)$ & $28.3(1)$ & \\
\hline \multirow{6}{*}{ Age (years) } & $19-29$ & 1586 & $14.5(1)$ & $22.8(0.7)$ & $11(1)$ & $<0.01$ \\
\hline & $30-39$ & 2612 & $15.6(1)$ & $22.5(0.7)$ & $16.3(1)$ & \\
\hline & $40-49$ & 2556 & $16.3(1)$ & $22.3(0.6)$ & $21.6(1)$ & \\
\hline & $50-59$ & 2867 & $17.6(1)$ & $16.7(0.5)$ & $23.5(1)$ & \\
\hline & $60-69$ & 2609 & $18.2(1)$ & $8.7(0.3)$ & $15.6(0.7)$ & \\
\hline & $\geq 70$ & 2260 & $17.9(1)$ & $7(0.3)$ & $11.9(0.6)$ & \\
\hline \multirow{3}{*}{ Sex } & Male & 5869 & $17.3(1)$ & $45.9(0.6)$ & $60.8(1)$ & $<0.01$ \\
\hline & Menstruating women & 4271 & $14.5(1)$ & $35.7(0.6)$ & $16.9(1)$ & \\
\hline & Menopausal women & 4350 & $17.1(1)$ & $18.4(0.5)$ & $22.3(1)$ & \\
\hline \multirow{3}{*}{ Obesity } & Underweight & 634 & $14.9(1)$ & $5(0.3)$ & $3.5(0.4)$ & $<0.01$ \\
\hline & Normal & 9234 & $16.3(1)$ & $63.3(0.6)$ & $63.2(1)$ & \\
\hline & Overweight & 4585 & $16.6(1)$ & $31.7(0.7)$ & $33.3(1)$ & \\
\hline \multirow{2}{*}{ Hypertension } & No & 11043 & $16.1(1)$ & $84.6(0.5)$ & $78.3(1)$ & $<0.01$ \\
\hline & Yes & 3447 & $17.5(1)$ & $15.4(0.5)$ & $21.7(1)$ & \\
\hline \multirow{2}{*}{ Diabetes } & No & 13241 & $16.2(1)$ & $94.5(0.3)$ & $91.5(0.5)$ & $<0.01$ \\
\hline & Yes & 1249 & $17.6(1)$ & $5.5(0.3)$ & $8.5(0.5)$ & \\
\hline \multirow{2}{*}{ Dyslipidemia } & No & 12798 & $16.2(1)$ & $92.2(0.3)$ & $89.4(0.5)$ & $<0.01$ \\
\hline & Yes & 1692 & $17.4(1)$ & $7.8(0.3)$ & $10.6(0.5)$ & \\
\hline \multirow{3}{*}{ Smoking status } & Non-smoker & 8829 & $15.8(1)$ & $56.9(0.6)$ & $45.9(1)$ & $<0.01$ \\
\hline & Ex-smoker & 2967 & $17.6(1)$ & $18.1(0.5)$ & $27.2(1)$ & \\
\hline & Smoker & 2694 & $16.5(1)$ & $25.1(0.6)$ & $26.9(1)$ & \\
\hline \multirow{3}{*}{ Alcohol consumption } & None & 4186 & $16.2(1)$ & $22.5(0.6)$ & $22.2(1)$ & $<0.01$ \\
\hline & Occasional (<2/week) & 7416 & $15.9(1)$ & $56.7(0.7)$ & $49.1(1)$ & \\
\hline & Frequent $(\geq 2 /$ week $)$ & 2888 & $17.5(1)$ & $20.9(0.6)$ & $28.7(1)$ & \\
\hline \multirow{2}{*}{ Regular exercise } & No & 7694 & $16.1(1)$ & $52.8(0.7)$ & $48.3(1)$ & $<0.01$ \\
\hline & Yes & 6796 & $16.6(1)$ & $47.2(0.7)$ & $51.7(1)$ & \\
\hline \multirow{2}{*}{ Region of residence } & Rural & 4844 & $17.8(1)$ & $25.2(1)$ & $40.7(2)$ & $<0.01$ \\
\hline & Urban & 9646 & $15.7(1)$ & $74.8(1)$ & $59.3(2)$ & \\
\hline \multirow{2}{*}{ Family income } & $<50^{\text {th }}$ percentile & 6573 & $16.6(1)$ & $41(1)$ & $46.3(1)$ & $<0.01$ \\
\hline & $\geq 50^{\text {th }}$ percentile & 7917 & $16.2(1)$ & $59(1)$ & $53.7(1)$ & \\
\hline \multirow{2}{*}{ Educational level } & Middle school or lower & 5397 & $17.8(1)$ & $23.8(0.7)$ & $37.9(1)$ & $<0.01$ \\
\hline & High school or higher & 9093 & $15.8(1)$ & $76.2(0.7)$ & $62.1(1)$ & \\
\hline \multirow{3}{*}{ Occupation } & White collar & 4604 & $15.8(1)$ & $40.4(1)$ & $30.5(1)$ & $<0.01$ \\
\hline & Blue collar & 3887 & $17.8(1)$ & $23.3(0.7)$ & $38.4(1)$ & \\
\hline & Unemployed & 5999 & $15.8(1)$ & $36.3(0.6)$ & $31.2(1)$ & \\
\hline \multirow{3}{*}{$\begin{array}{l}\text { Sleep duration (hours/ } \\
\text { day) }\end{array}$} & $<6$ & 2226 & $16.5(1)$ & $12.9(0.4)$ & $13.3(0.7)$ & 0.48 \\
\hline & 6 to 9 & 11798 & $16.3(1)$ & \begin{tabular}{|l|}
$83.5(0.5)$ \\
\end{tabular} & $83.6(0.7)$ & \\
\hline & $\geq 10$ & 466 & $15.7(1)$ & $3.6(0.2)$ & $3.1(0.3)$ & \\
\hline \multirow{2}{*}{$\begin{array}{l}\text { Exposure to sunlight } \\
\text { (hours/day) }\end{array}$} & $<2$ & 9173 & $15.8(1)$ & $66.4(1)$ & $53.5(1)$ & $<0.01$ \\
\hline & $\geq 2$ & 5317 & $17.3(1)$ & $33.6(1)$ & $46.5(1)$ & \\
\hline
\end{tabular}

Table 2. Vitamin D status by participant characteristics. p-Values were calculated by Rao-Scott chi-square test.

Association of vitamin D status with baseline characteristics and association of sleep duration with vitamin D sufficiency/deficiency. Vitamin D status in participants were analyzed with respect to age, sex, obesity, HTN, DM, dyslipidemia, smoking status, alcohol consumption, regular exercise, region of residence, family income, education level, occupation, and exposure to sunlight. Participants were also divided according to vitamin D status into a deficiency group $(<20 \mathrm{ng} / \mathrm{mL}, 71.74 \%)$ and a sufficiency group $(\geq 20 \mathrm{ng} / \mathrm{mL}$, $28.26 \%$ ), and groups were analyzed for an association with baseline characteristics (Table 2). Vitamin D status were higher in participants who were elderly, overweight, hypertensive, diabetic, and dyslipidemic and lower in menstruating women. Participants with appropriate vitamin D status were more likely to participate in regular exercise, live in a rural area, have a low familial income and educational level, be blue collar workers, and have adequate sun exposure. Vitamin D status were relatively high in the participants with sleep insufficiency.

The vitamin D deficiency and sufficiency groups showed significant differences in terms of age, sex, obesity, HTN, DM, dyslipidemia, smoking status, alcohol consumption, regular exercise, region of residence, family income, education level, occupation, and exposure to sunlight. However, no significant difference was observed between $25(\mathrm{OH}) \mathrm{D}$ groups in terms of sleep duration. 


\begin{tabular}{|l|l|l|l|l|l|l|}
\hline \multirow{2}{*}{ Variable } & \multicolumn{5}{|l|}{ Sleep duration (hours/day) } \\
\cline { 2 - 7 } & $\mathbf{N}$ & $<\mathbf{6}(\mathbf{N}=\mathbf{2 2 2 6})$ & $\mathbf{6}$ to $\mathbf{9}(\mathbf{N}=\mathbf{1 1 7 9 8})$ & $\geq \mathbf{1 0}(\mathbf{N}=\mathbf{4 6 6})$ & p-value \\
\hline $\begin{array}{l}\text { Exposure } \\
\text { to sunlight } \\
\text { (hours/day) }\end{array}$ & $<2$ & 9173 & $16.1(1)$ & $15.8(1)$ & $14.4(1)$ & $<\mathbf{0 . 0 1}$ \\
\cline { 2 - 7 } & 22 & 5317 & $17.2(1)$ & $17.3(1)$ & $17.8(1)$ & 0.48 \\
\hline
\end{tabular}

Table 3. Vitamin D status by sleep duration and sun exposure. Data were reported as geometric mean (standard error, SE). p-Values were calculated by analysis of variance.

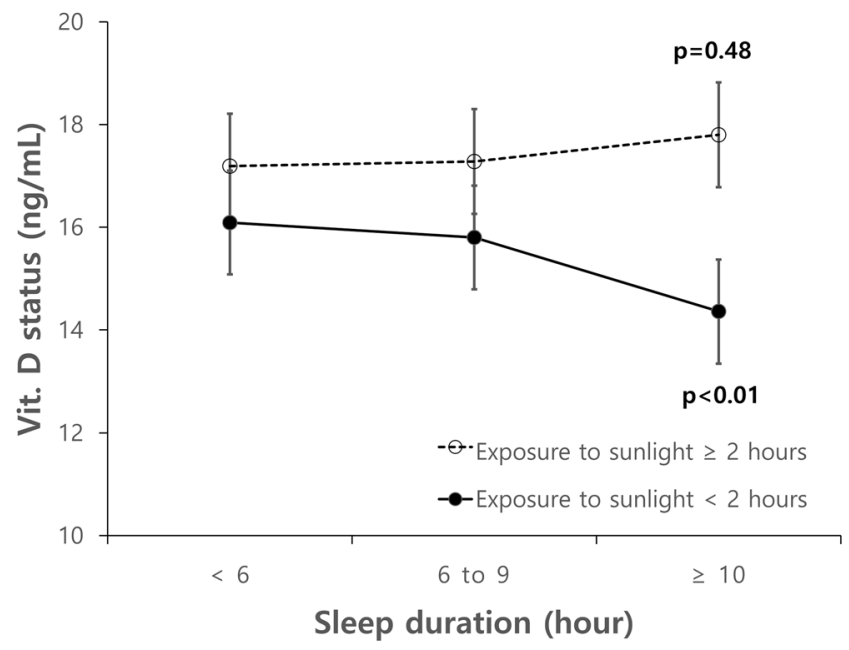

Figure 1. Distribution of Vit. D status.

Multiple logistic regression analyses of vitamin D status, sleep duration, and exposure to sunlight. Multiple logistic regression analyses were performed because of the conflicting evidence that there was no significant difference between the sleep duration groups and sun exposure, but there was a statistical difference in sleep duration within participants with low sun exposure (Table 3 and Fig. 1).

To accurately assess the relationship between sleep duration, sun exposure, and vitamin D status, confounding factors of vitamin D status and sleep duration identified during this study were controlled through multiple logistic regression analysis. Differences in log-transformed vitamin D status between the sleep insufficient or excessive sleep groups and the normal-range sleep group were not significant. However, vitamin D status were significantly lower in the low exposure to sunlight group than in the adequate exposure to sunlight group, even after controlling for confounding variables $(\beta=0.91)$ (Table 4$)$.

\section{Discussion}

$25(\mathrm{OH}) \mathrm{D}$ is known to be involved in the metabolism of calcium and phosphate for the maintenance of musculoskeletal health, but recent clinical studies have suggested it may also be involved in chronic metabolic disease. Research has shown that 25(OH)D receptors are present in most cells of the body and produce a variety of symptoms due to the hormone-like effects of $25(\mathrm{OH}) \mathrm{D}$. Vitamin D deficiency is often overlooked because of the lack of outward symptoms. UV light exogenously triggers $25(\mathrm{OH}) \mathrm{D}$ production, and $25(\mathrm{OH}) \mathrm{D}$ can be supplemented through food intake. Differences in the bioavailability of $25(\mathrm{OH}) \mathrm{D}$ have been reported to depend on the form, route of administration, and activation pathway involved ${ }^{33}$. In modern society, it can be difficult to obtain adequate sun exposure because of an increase in indoor activities. Therefore, it is important to study the combined influence of low exposure to sunlight and other factors in vitamin D deficiency to indicate more achievable measures that can be taken against this condition. Our study investigated vitamin D deficiency from this angle, and in line with previous reports, we found that sun exposure and vitamin D status have a significant association. This is a natural consequence of the $25(\mathrm{OH}) \mathrm{D}$ activation pathway. However, unlike previous studies, we also analyzed the relationship between sleep duration and vitamin D status in detail. We found no significant difference between vitamin D status and sleep duration in individuals who were exposed to adequate sunlight. However, in participants with insufficient sun exposure, we found that individuals with excessive sleep duration had relatively low levels of $25(\mathrm{OH}) \mathrm{D}$, even after controlling for potentially confounding variables.

A previous study reported that shorter sleep duration was associated with lower vitamin D status in the elderly ${ }^{34}$, though the data were limited by the age group of the study population and did not sufficiently control for sun exposure and other confounding factors. Another study found a relationship between sleep apnea and vitamin D status, but did not analyze other characteristics of sleep duration ${ }^{35}$. Although vitamin $\mathrm{D}$ supplements have been reported to improve sleep quality ${ }^{36}$, their effect on serum vitamin D status and sleep duration has not been assessed. 


\begin{tabular}{|c|c|c|c|c|c|c|c|c|c|}
\hline \multirow{2}{*}{\multicolumn{2}{|c|}{ Independent variable }} & \multicolumn{2}{|l|}{ Model 1} & \multicolumn{2}{|l|}{ Model 2} & \multicolumn{2}{|l|}{ Model 3} & \multicolumn{2}{|l|}{ Model 4} \\
\hline & & \multirow{2}{*}{\begin{tabular}{|l|}
$\boldsymbol{\beta}(\mathbf{9 5} \% \mathbf{C I})$ \\
$0.99(1)$ \\
\end{tabular}} & \multirow{2}{*}{\begin{tabular}{|l|}
$\mathbf{p}$-value \\
0.74
\end{tabular}} & \multirow{2}{*}{\begin{tabular}{|l|}
$\boldsymbol{\beta}(\mathbf{9 5} \% \mathbf{C I})$ \\
$0.97(1)$
\end{tabular}} & \multirow{2}{*}{\begin{tabular}{|l|}
$\mathbf{p}$-value \\
0.06
\end{tabular}} & \multirow{2}{*}{\begin{tabular}{|l|}
$\boldsymbol{\beta}(\mathbf{9 5} \% \mathbf{C I})$ \\
$0.97(1)$ \\
\end{tabular}} & \multirow{2}{*}{\begin{tabular}{|l|} 
p-value \\
0.06
\end{tabular}} & \multirow{2}{*}{\begin{tabular}{|l|}
$\boldsymbol{\beta}(\mathbf{9 5} \% \mathrm{CI})$ \\
$0.97(1)$
\end{tabular}} & \multirow{2}{*}{\begin{tabular}{|l|} 
p-valu \\
0.07
\end{tabular}} \\
\hline \multirow{3}{*}{ Sleep duration (hour) } & $<6$ & & & & & & & & \\
\hline & 6 to 9 & 1 (Ref) & & 1 (Ref) & & 1 (Ref) & & 1 (Ref) & \\
\hline & $\geq 10$ & $1.03(1)$ & 0.27 & $1.04(1)$ & 0.17 & $1.04(1)$ & 0.17 & $1.03(1)$ & 0.26 \\
\hline \multirow{2}{*}{$\begin{array}{l}\text { Exposure to sunlight } \\
\text { (hour) }\end{array}$} & $<2$ & $0.91(1)$ & $<0.01$ & $0.94(1)$ & $<0.01$ & $0.94(1)$ & $<0.01$ & $0.96(1)$ & $<0.01$ \\
\hline & $\geq 2$ & 1 (Ref) & & 1 (Ref) & & 1 (Ref) & & 1 (Ref) & \\
\hline \multirow{3}{*}{ Interaction terms } & $\begin{array}{l}\text { ETS }<2 \& \\
\text { sleep duration }<6\end{array}$ & $1.02(1)$ & 0.25 & $1.01(1)$ & 0.53 & $1.01(1)$ & 0.53 & $1.01(1)$ & 0.49 \\
\hline & $\begin{array}{l}\text { ETS }<2 \& \\
\text { sleep duration } 6 \text { to } 9\end{array}$ & 1 (Ref) & & 1 (Ref) & & 1 (Ref) & & 1 (Ref) & \\
\hline & \begin{tabular}{|l|} 
ETS $<2 \&$ \\
sleep duration $\geq 10$
\end{tabular} & $0.88(1)$ & $<0.01$ & $0.9(1)$ & $<0.01$ & $0.91(1)$ & $<0.01$ & $0.91(1)$ & 0.02 \\
\hline
\end{tabular}

Table 4. Exponentiated beta coefficients and $95 \%$ confidence intervals of log-transformed vitamin D status. *Exponentiated value providing ratio; ETS, exposure to sunlight. Model 1: Crude model. Model 2: Model 1 adjusted for age and sex. Model 3: Model 2 adjusted for physical status (obesity, prevalent hypertension, prevalent diabetes, and prevalent dyslipidemia). Model 4: Model 3 adjusted for lifestyle status (smoking status, drinking status, and regular exercise) and socio-demographic factors (family income, educational level, occupation, and region of residence).

This study was based on a population-based epidemiologic dataset and controlled for the effect of sun exposure on vitamin D status to mimic life in a contemporary society. Results were statistically significant, even when potentially confounding variables were controlled. However, the factors such as adequate sleep duration and exposure to sunlight vary depending on the person and the given environment, so the lack of sufficient reflection of these factors may be a limitation of our research. In addition, because sleep duration and sun exposure were determined from participant responses to a questionnaire, the accuracy of these data may be limited by leading question bias or recall bias.

In this study, we found that low serum vitamin D status are associated with excessive sleep duration in individuals with low sun exposure. Therefore, in modern society where sun exposure is inevitably low, maintaining an adequate serum vitamin $\mathrm{D}$ status may be important for a healthy sleep duration.

\section{Conclusion}

Therefore, we analyzed the relationship between sleep duration and vitamin D status in the low exposure to sunlight group. There was no significant difference between vitamin D status in the sleep insufficiency and normal-range sleep groups. However, the excessive sleep group had significantly lower levels of 25(OH)D than the normal-range sleep group, even after controlling for confounding variables.

Received: 24 October 2019; Accepted: 20 February 2020;

Published online: 06 March 2020

\section{References}

1. Ohayon, M. M., Reynolds, C. F. III \& Dauvilliers, Y. Excessive sleep duration and quality of life. Annals of neurology 73, 785-794, https://doi.org/10.1002/ana.23818 (2013).

2. Pergola, B. L., Moonie, S., Pharr, J., Bungum, T. \& Anderson, J. L. Sleep duration associated with cardiovascular conditions among adult Nevadans. Sleep medicine 34, 209-216, https://doi.org/10.1016/j.sleep.2017.03.006 (2017).

3. Grandner, M. A. \& Drummond, S. P. Who are the long sleepers? Towards an understanding of the mortality relationship. Sleep medicine reviews 11, 341-360, https://doi.org/10.1016/j.smrv.2007.03.010 (2007).

4. Tan, X., Chapman, C. D., Cedernaes, J. \& Benedict, C. Association between long sleep duration and increased risk of obesity and type 2 diabetes: A review of possible mechanisms. Sleep medicine reviews 40, 127-134, https://doi.org/10.1016/j.smrv.2017.11.001 (2018).

5. Orzel-Gryglewska, J. Consequences of sleep deprivation. International journal of occupational medicine and environmental health $\mathbf{2 3}$, 95-114, https://doi.org/10.2478/v10001-010-0004-9 (2010).

6. Obayashi, K. et al. Positive effect of daylight exposure on nocturnal urinary melatonin excretion in the elderly: a cross-sectional analysis of the HEIJO-KYO study. The Journal of clinical endocrinology and metabolism 97, 4166-4173, https://doi.org/10.1210/ jc.2012-1873 (2012).

7. Golan, D. et al. The influence of vitamin D supplementation on melatonin status in patients with multiple sclerosis. Brain, behavior, and immunity 32, 180-185, https://doi.org/10.1016/j.bbi.2013.04.010 (2013).

8. Adamsson, M., Laike, T. \& Morita, T. Annual variation in daily light exposure and circadian change of melatonin and cortisol concentrations at a northern latitude with large seasonal differences in photoperiod length. Journal of physiological anthropology 36, 6, https://doi.org/10.1186/s40101-016-0103-9 (2016).

9. Duzgun, G. \& Durmaz Akyol, A. Effect of Natural Sunlight on Sleep Problems and Sleep Quality of the Elderly Staying in the Nursing Home. Holistic nursing practice 31, 295-302, https://doi.org/10.1097/hnp.0000000000000206 (2017).

10. Baradaran Mahdavi, S. et al. Association of Sunlight Exposure with Sleep Hours in Iranian Children and Adolescents: The CASPIAN-V Study. Journal of tropical pediatrics, https://doi.org/10.1093/tropej/fmz023 (2019).

11. Smolensky, M. H., Sackett-Lundeen, L. L. \& Portaluppi, F. Nocturnal light pollution and underexposure to daytime sunlight: Complementary mechanisms of circadian disruption and related diseases. Chronobiology international 32, 1029-1048, https://doi. org/10.3109/07420528.2015.1072002 (2015).

12. Mitri, J., Muraru, M. D. \& Pittas, A. G. Vitamin D and type 2 diabetes: a systematic review. European journal of clinical nutrition 65 , 1005-1015, https://doi.org/10.1038/ejcn.2011.118 (2011). 
13. Forman, J. P. et al. Plasma 25-hydroxyvitamin D levels and risk of incident hypertension. Hypertension (Dallas, Tex.: 1979) 49, 1063-1069, https://doi.org/10.1161/hypertensionaha.107.087288 (2007).

14. Hollams, E. M. et al. Vitamin D and atopy and asthma phenotypes in children: a longitudinal cohort study. The European respiratory journal 38, 1320-1327, https://doi.org/10.1183/09031936.00029011 (2011).

15. Gominak, S. C. Vitamin D deficiency changes the intestinal microbiome reducing B vitamin production in the gut. The resulting lack of pantothenic acid adversely affects the immune system, producing a "pro-inflammatory" state associated with atherosclerosis and autoimmunity. Medical hypotheses 94, 103-107, https://doi.org/10.1016/j.mehy.2016.07.007 (2016).

16. Muscogiuri, G. et al. The lullaby of the sun: the role of vitamin D in sleep disturbance. Sleep medicine 54, 262-265, https://doi. org/10.1016/j.sleep.2018.10.033 (2019).

17. Tsiaras, W. G. \& Weinstock, M. A. Factors influencing vitamin D status. Acta dermato-venereologica 91, 115-124, https://doi. org/10.2340/00015555-0980 (2011).

18. Pludowski, P. et al. Vitamin D effects on musculoskeletal health, immunity, autoimmunity, cardiovascular disease, cancer, fertility, pregnancy, dementia and mortality-a review of recent evidence. Autoimmunity reviews 12, 976-989, https://doi.org/10.1016/j. autrev.2013.02.004 (2013)

19. Gominak, S. C. \& Stumpf, W. E. The world epidemic of sleep disorders is linked to vitamin D deficiency. Medical hypotheses 79, 132-135, https://doi.org/10.1016/j.mehy.2012.03.031 (2012).

20. McCarty, D. E. Resolution of hypersomnia following identification and treatment of vitamin d deficiency. Journal of clinical sleep medicine: JCSM: official publication of the American Academy of Sleep Medicine 6, 605-608 (2010).

21. McCarty, D. E., Chesson, A. L. Jr., Jain, S. K. \& Marino, A. A. The link between vitamin D metabolism and sleep medicine. Sleep medicine reviews 18, 311-319, https://doi.org/10.1016/j.smrv.2013.07.001 (2014).

22. Grandner, M. A., Kripke, D. F., Naidoo, N. \& Langer, R. D. Relationships among dietary nutrients and subjective sleep, objective sleep, and napping in women. Sleep medicine 11, 180-184, https://doi.org/10.1016/j.sleep.2009.07.014 (2010).

23. Johnsen, M. T., Wynn, R., Allebrandt, K. \& Bratlid, T. Lack of major seasonal variations in self reported sleep-wake rhythms and chronotypes among middle aged and older people at 69 degrees North: the Tromso Study. Sleep medicine 14, 140-148, https://doi. org/10.1016/j.sleep.2012.10.014 (2013).

24. McCarty, D. E., Reddy, A., Keigley, Q., Kim, P. Y. \& Marino, A. A. Vitamin D, race, and excessive daytime sleepiness. Journal of clinical sleep medicine: JCSM: official publication of the American Academy of Sleep Medicine 8, 693-697, https://doi.org/10.5664/ jcsm.2266 (2012).

25. Sato-Mito, N. et al. The midpoint of sleep is associated with dietary intake and dietary behavior among young Japanese women. Sleep medicine 12, 289-294, https://doi.org/10.1016/j.sleep.2010.09.012 (2011).

26. Grandner, M. A., Jackson, N., Gerstner, J. R. \& Knutson, K. L. Sleep symptoms associated with intake of specific dietary nutrients. J Sleep Res. 23, 22-34, https://doi.org/10.1111/jsr.12084 (2014).

27. Grandner, M. A., Jackson, N., Gerstner, J. R. \& Knutson, K. L. Dietary nutrients associated with short and long sleep duration. Data from a nationally representative sample. Appetite 64, 71-80, https://doi.org/10.1016/j.appet.2013.01.004 (2013)

28. Min, H. et al. Association between Sleep Duration and Measurable Cardiometabolic Risk Factors in Healthy Korean Women: The Fourth and Fifth Korean National Health and Nutrition Examination Surveys (KNHANES IV and V). International journal of endocrinology 2016, 3784210, https://doi.org/10.1155/2016/3784210 (2016).

29. Sempos, C. T., Vesper, H. W., Phinney, K. W., Thienpont, L. M. \& Coates, P. M. Vitamin D status as an international issue: national surveys and the problem of standardization. Scandinavian journal of clinical and laboratory investigation. Supplementum 243, 32-40, https://doi.org/10.3109/00365513.2012.681935 (2012).

30. Holick, M. F. \& Chen, T. C. Vitamin D deficiency: a worldwide problem with health consequences. The American journal of clinical nutrition 87, 1080s-1086s, https://doi.org/10.1093/ajcn/87.4.1080S (2008).

31. Ross, A. C. et al. The 2011 report on dietary reference intakes for calcium and vitamin D from the Institute of Medicine: what clinicians need to know. The Journal of clinical endocrinology and metabolism 96, 53-58, https://doi.org/10.1210/jc.2010-2704 (2011).

32. Rosen, C. J. Clinical practice. Vitamin D insufficiency. N. Engl. J. Med. 364, 248-254, https://doi.org/10.1056/NEJMcp1009570 (2011)

33. Holick, M. F. Vitamin D deficiency. N. Engl. J. Med. 357, 266-281, https://doi.org/10.1056/NEJMra070553 (2007)

34. Kim, J. H., Chang, J. H., Kim, D. Y. \& Kang, J. W. Association between self-reported sleep duration and serum vitamin D level in elderly Korean adults. J. Am. Geriatr. Soc. 62, 2327-2332, https://doi.org/10.1111/jgs.13148 (2014).

35. Piovezan, R. D. et al. Obstructive sleep apnea and objective short sleep duration are independently associated with the risk of serum vitamin D deficiency. PloS one 12, e0180901, https://doi.org/10.1371/journal.pone.0180901 (2017).

36. Majid, M. S., Ahmad, H. S., Bizhan, H., Mohammad Hosein, H. Z. \& Mohammad, A. The effect of vitamin D supplement on the score and quality of sleep in 20-50 year-old people with sleep disorders compared with control group. Nutr. Neurosci., 1-9, https:// doi.org/10.1080/1028415X.2017.1317395 (2017).

\section{Acknowledgements}

This was not an industry-supported study. This work was supported by the National Research Foundation of Korea Grant funded by the Korean Government (NRF-2019R1A2C4002468). This study was also supported by the Soonchunhyang University Research Fund. The funders had no role in study design, data collection and analysis, decision to publish, or preparation of the manuscript.

\section{Author contributions}

Conceptualization: Do-Yang Park, Ji Ho Choi. Data curation: Dong Young Kim, Ji Ho Choi. Formal analysis: Bora Lee, Bumhee Park. Funding acquisition: Do-Yang Park, Ji Ho Choi. Methodology: Bora Lee, Bumhee Park. Supervision: Do-Yang Park. Validation: Jae Yong Lee, Hyun Jun Kim, Chang-Hoon Kim. Writing - original draft: Do-Yang Park, Ji Ho Choi. Writing - review \& editing: Do-Yang Park, Ji Ho Choi.

\section{Competing interests}

The authors declare no competing interests.

\section{Additional information}

Correspondence and requests for materials should be addressed to D.-Y.P.

Reprints and permissions information is available at www.nature.com/reprints. 
Publisher's note Springer Nature remains neutral with regard to jurisdictional claims in published maps and institutional affiliations.

(c) (i) Open Access This article is licensed under a Creative Commons Attribution 4.0 International License, which permits use, sharing, adaptation, distribution and reproduction in any medium or format, as long as you give appropriate credit to the original author(s) and the source, provide a link to the Creative Commons license, and indicate if changes were made. The images or other third party material in this article are included in the article's Creative Commons license, unless indicated otherwise in a credit line to the material. If material is not included in the article's Creative Commons license and your intended use is not permitted by statutory regulation or exceeds the permitted use, you will need to obtain permission directly from the copyright holder. To view a copy of this license, visit http://creativecommons.org/licenses/by/4.0/.

(c) The Author(s) 2020 